\title{
Association of polymorphism in the interferon $\gamma$ gene with IDDM
}

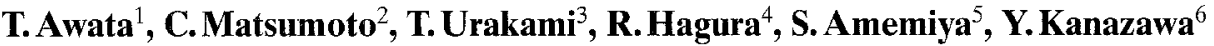 \\ ${ }^{1}$ Department of Pathology, University of Massachusetts Medical Center, Worcester, Mass., USA \\ ${ }^{2}$ Division of Endocrinology and Metabolism, Jichi Medical School, Tochigi, Japan \\ ${ }^{3}$ Department of Pediatrics, Nihon University, School of Medicine, Tokyo, Japan \\ ${ }^{4}$ Institute for Diabetes Care and Research, Asahi Life Foundation, Tokyo, Japan \\ ${ }^{5}$ Department of Pediatrics, University of Yamanashi Medical School, Yamanashi, Japan \\ ${ }^{6}$ Omiya Medical Center, Jichi Medical School, Omiya, Japan
}

Summary Cytokines may play importmant roles in the pathogenesis of insulin-dependent diabetes mellitus (IDDM). We analysed a dinucleotide repeat polymorphism within the first intron of the interferon $\gamma($ IFN- $\gamma)$ gene in Japanese diabetic patients (175 IDDM and 145 non-insulin-dependent diabetes mellitus) and 267 control subjects. A significant difference was observed in the global allele distribution of the polymorphism between the IDDM and control groups $(p=0.039)$. The difference from the control group was more evident in the patients whose insulin therapy started within 1 year from onset $(p=0.006)$ or in the young-onset $(<10$ years $)$ patients $(p=0.0006)$. The alleles " 3 " and " 6 " were increased in the IDDM patients, and a significant increase in the frequency of the " $3 / 6$ " genotype was observed in the IDDM patient group $(9.1 \%$, RR 2.9 , $p=0.010)$, in the patients with initial insulin therapy less than 1 year from onset $(10.6 \%$, RR 3.4 , $p=0.004)$, or in the young-onset patients $(16.7 \%$, RR 5.7, $p=0.0003)$ in comparison to the control subjects $(3.4 \%)$. There was a tendency towards frequent occurrence of clinical characteristics which reflect young or abrupt onset of diabetes or both, and depletion of insulin secretion capacity in the patients with " $3 / 6$ " or " $6 / 6$ " in comparison to the patients with other genotypes. These results suggest that the IFN$\gamma$ gene region may contribute to the pathogenesis of IDDM and could be a genetic marker for IDDM. [Diabetologia (1994) 37: 1159-1162]

Key words Interferon gamma, gene, polymorphism, association, insulin dependent diabetes mellitus, susceptibility, Japanese.
Abundant evidence suggests that insulin-dependent diabetes mellitus (IDDM) is caused by the destruction of pancreatic beta cells resulting from $T$ lymphocyte-mediated autoimmune process. It is well established that the HLA class II region contributes to the development of IDDM. Furthermore, in Cauca-

Received: 20 June 1994

and in revised form: 29 July 1994

Corresponding author: Dr. T. Awata, Department of Pathology, University of Massachusetts Medical Center, 55 Lake Avenue North, Worcester, MA 01655, USA

Abbreviations: IDDM, Insulin-dependent diabetes mellitus; HLA, human leucocyte antigen; IFN- $\gamma$, interferon $\gamma$; NIDDM, non-insulin-dependent diabetes mellitus; PCR, polymerase chain reaction; ICA, islet cell antibody; TNF- $\beta$, tumour necrosis factor $\beta$; IL- $1 \beta$, interleukin- $\beta$; INS, insulin gene. sians, polymorphisms near the insulin gene (INS) were associated with IDDM [1], suggesting that the INS region is another susceptibility locus for IDDM. However, the HLA and INS are insufficient to account for the familial clustering of IDDM.

The candidate gene approach is one of the useful strategies for elucidating additional susceptibility genes for IDDM. A number of studies suggest that cytokines may play roles in the pathogenesis of IDDM [2]. In particular, IFN- $\gamma$ produced by immune/inflammatory cells may be important, since it has been reported that (1) IFN- $\gamma$ upregulates MHC class I, class II antigens and adhesion molecules on various cells including pancreatic beta cells; (2) IFN$\gamma$ is directly cytotoxic to islet cells; and (3) IFN- $\gamma$ activates cytotoxic macrophages and $\mathrm{T}$ lymphocytes. In addition, transgenic mice expressing IFN $-\gamma$ by beta cells develop autoimmune diabetes, and monoclonal 
antibodies to IFN- $\gamma$ protect against diabetes development in NOD mice and BB rats. Therefore, subsequent to the studies of HLA class II alleles and INS polymorphisms [3, 4], we analysed polymorphism in the IFN- $\gamma$ gene and its association with IDDM in Japanese subjects.

\section{Subjects and methods}

Subjects. We recruited 175 IDDM and 145 NIDDM patients from the hospitals or clinics in the Kanto district (Tokyo or adjacent prefectures), Japan. We randomly selected 267 control subjects also living in the Kanto district. The diagnosis of IDDM or NIDDM was based on the criteria of National Diabetes Data Group. The mean age at onset of IDDM and NIDDM was 22.6 years and 47.0, respectively. Informed consent was made by each individual, and the study was conducted in accordance with the principles of the Declaration of Helsinki.

Methods. Genomic DNA was extracted from peripheral blood. In the present study, we analysed a CA repeat polymorphism within intron 1 of the IFN- $\gamma$ gene [5]. The IFN- $\gamma$ gene is single copy and located on the long arm of chromosome 12. DNA was subjected to 35 cycles of polymerase chain reaction (PCR) amplification, each cycle consisting of $60 \mathrm{~s}$ at $94^{\circ} \mathrm{C}$, $30 \mathrm{~s}$ at $48^{\circ} \mathrm{C}$, and $40 \mathrm{~s}$ at $72^{\circ} \mathrm{C}$. The reaction volume was $5 \mu \mathrm{l}$ containing $10-50 \mathrm{ng}$ of genomic DNA, 2 pmol each of primers (forward: 5' -- TCACAATTGATTTTATTCTTAC-3', reverse: $5^{\prime}$ - TGCCTTCCTGTAGGGTATTATT-3 ${ }^{\prime}$ ), $0.2 \mathrm{mmol} /$ 1 each dNTP, $2 \mathrm{mmol} / 1 \mathrm{Mg}^{2+}$ and $0.2 \mathrm{u}$ thermostable DNA polymerase. The PCR products were electrophoresed on a $10 \%$ neutral polyacrylamide gel $(0.4 \mathrm{~mm}$ thick $)$ and visualized by silver staining.

\section{Statistical analysis}

Frequencies of alleles and genotypes were estimated from the observed data. Hardy-Weinberg equilibrium was assessed for the genotype distribution. Global allele distribution was analysed by chi-square analysis with $2 \times 6$ contingency tables after rare alleles ("2", "5", " 8 ") had been combined. Differences between allele or genotype frequencies of groups were evaluated by chi-square analysis with $2 \times 2$ contingency tables. When at least one cell number was not more than 5, Yates' correction was applied for the chi-square value. Relative risks (RR) were calculated by Woolf's formula. Ages at onset between groups were compared by unpaired two-tailed Student's $t$ test, and the other categorical clinical data were compared by chi-square analysis.

\section{Results}

Figure 1 illustrates examples of the IFN- $\gamma$ polymorphism. A total of eight different-size alleles were detected (designated " 1 " through " 8 "). Table 1 (upper panel) summarizes the allele frequencies of the IFN- $\gamma$ polymorphism in 267 control subjects, 175 IDDM and 145 NIDDM patients. The global allele distribution in the IDDM patients was signifi-

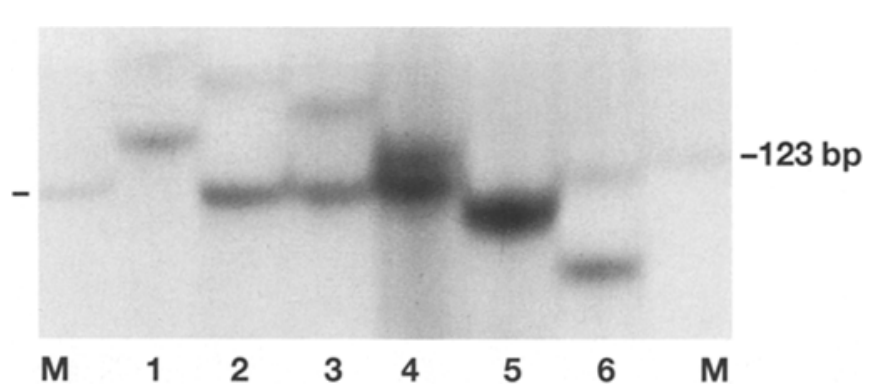

Fig. 1. PCR products of CA repeat within the first intron of the interferon- $\gamma$ gene. Lanes M contain 123 base pair (bp) DNA ladder markers. Eight alleles (designated "1" through "8") were detected in this region. Genotypes of lanes 1-6 are " 1 / 4 ", " $2 / 6 "$, " $3 / 6 "$, " $5 / 6 "$, " $7 / 7$ ", and " $6 / 8$ ", respectively

cantly different from that in the control subjects $(p=0.039)$ and also that in the NIDDM patients $(p=0.013)$, but the distribution did not differ significantly between the NIDDM and control groups. In Japanese IDDM patients, slow progression of the disease is a frequent feature. In the present IDDM group, 43 patients did not require insulin treatment within 1 year after the onset of diabetes. When we excluded such patients, the difference of allele distribution with the control subjects was more evident $(p=0.006)$. Furthermore, there was a highly significant $(p=0.0006)$ difference between the IDDM patients with age at onset under 10 years and the control subjects. The alleles " 3 " and " 6 " were increased in the patients, and significant increase of the frequency of the "3/6" genotype was observed in the whole IDDM patient group (9.1\%, RR 2.9, $p=0.010$ ), in the patients with initial insulin therapy less than 1 year from onset $(10.6 \%$, RR 3.4 , $p=0.004)$, or in the young-onset patients $(16.7 \%$, RR 5.7, $p=0.0003$ ) in comparison to the control subjects $(3.4 \%)$. In addition, the combined frequency of the " $3 / 6$ " and " $6 / 6$ " genotpyes (" $3 / 3$ " was not observed) was significantly increased in the above patient groups (RR 1.8, $p=0.007$; RR 2.1, $p=0.0007$; RR 3.0, $p=0.0009$, respectively). The genotype frequencies in control or patient groups did not deviate from the expected value by Hardy-Weinberg equilibrium (data not shown).

As shown in the lower panel of Table 1, some clinical characteristics were compared between the IDDM patients with " $3 / 6$ " or " $6 / 6$ " genotypes and the patients with other genotypes. The frequency of the patients who did not require insulin treatment within 1 year from onset, reflecting slow progression of IDDM, was significantly less in the group with " $3 / 6$ " or " $6 / 6$ " $(p=0.030)$. The frequency of insulin-preserved IDDM patients, defined as those with a post-prandial $\mathrm{C}$-peptide value not less than $0.1 \mathrm{nmol} / \mathrm{l}$ after 3 years from onset, was also decreased in the group with " $3 / 6$ " or " $6 / 6$ ", although it was not significant $(p=0.103)$. Autoimmune thyr- 
Table 1. Allele frequencies of the interferon- $\gamma$ gene polymorphism (upper panel) and clinical characteristics of IDDM patients (lower panel)

\begin{tabular}{|c|c|c|c|c|c|c|c|c|c|}
\hline Group & 1 & 2 & 3 & 4 & 5 & 6 & 7 & 8 & $P$-value ${ }^{a}$ \\
\hline $\begin{array}{l}\text { Control } \\
(534)\end{array}$ & $\begin{array}{l}0.024 \\
(13)\end{array}$ & $\begin{array}{l}0.004 \\
(2)\end{array}$ & $\begin{array}{l}0.024 \\
(13)\end{array}$ & $\begin{array}{l}0.320 \\
(171)\end{array}$ & $\begin{array}{l}0.011 \\
(6)\end{array}$ & $\begin{array}{l}0.493 \\
(263)\end{array}$ & $\begin{array}{l}0.124 \\
(66)\end{array}$ & $\begin{array}{l}0 \\
(0)\end{array}$ & - \\
\hline \multirow[t]{2}{*}{$\begin{array}{l}\text { NIDDM } \\
(290)\end{array}$} & $\begin{array}{l}0.014 \\
(4)\end{array}$ & $\begin{array}{l}0.003 \\
(1)\end{array}$ & $\begin{array}{l}0.024 \\
(7)\end{array}$ & $\begin{array}{l}0.352 \\
(102)\end{array}$ & $\begin{array}{l}0.024 \\
(7) \\
\end{array}$ & $\begin{array}{l}0.507 \\
(147) \\
\end{array}$ & $\begin{array}{l}0.072^{b} \\
(21)\end{array}$ & $\begin{array}{l}0.003 \\
(1)\end{array}$ & NS \\
\hline & & & \multicolumn{3}{|c|}{$" 3 / 6 "$ or " $6 / 6 "$} & \multicolumn{3}{|c|}{ Other genotypes } & Significance \\
\hline $\begin{array}{l}n \\
\text { Sex (male: female) } \\
\text { Age at onset (year; mean } \\
\text { Insulin required }>1 \text { year f } \\
\text { Postprandial serum C-pep } \\
\text { Associated autoimmune th }\end{array}$ & $\begin{array}{l}\text { D) } \\
m \text { onset } \\
\text { le } \geq 0.1 \\
\text { toid dis }\end{array}$ & $\mathrm{ol} / \mathrm{I}^{\mathrm{e}}$ & $\begin{array}{l}65 \\
26: 39 \\
21.2 \pm \\
15.4 \% \\
45.6 \% \\
15.4 \%\end{array}$ & $5 / 57)$ & & $\begin{array}{l}110 \\
50: 60 \\
23.4 \pm \\
30.0 \% \\
59.3 \% \\
9.1 \%\end{array}$ & /91) & & $\begin{array}{l}\text { NS } \\
\text { NS } \\
p=0.030 \\
\text { NS } \\
\text { NS }\end{array}$ \\
\hline
\end{tabular}

Observed number of each allele was given in parenthesis in upper panel.

${ }^{a}$ Global distribution of alleles between the patient groups and the control group was evaluated by chi-square analysis with $2 \times 6$ tables (rare alleles " 2 ", " 5 " and " 8 " were combined).

\footnotetext{
${ }^{\mathrm{b}} p<0.05,{ }^{\mathrm{c}} p<0.01$

d $p<0.001$ vs control.

e Post-prandial serum C-peptide response was measured at least 3 years after onset.

' Graves' disease or Hashimoto's thyroiditis.
}

oid disease (Graves' disease or Hashimoto's thyroiditis) is frequently associated with IDDM in Japanese subjects, as in Caucasians. The frequency of the patients who also had autoimmune thyroid disease was increased in the group with " $3 / 6$ " or " $6 / 6$ ", although it was not significant $(p=0.206)$. The frequency of islet cell antibody (ICA) positivity was not significantly different between the subgroups (data not shown).

\section{Discussion}

In the present study, we found an association of the polymorphism within the first intron of the IFN- $\gamma$ gene with IDDM. Although several earlier studies $[6,7]$ reported possible associations of tumour necrosis factor $\beta$ (TNF- $\beta$ ) and interleukin- $1 \beta$ (IL- $1 \beta$ ) polymorphisms, this is, to our knowledge, the first description of association between IDDM and an IFN- $\gamma$ polymorphism. One should be cautious about the positive association, since multiple factors could give erroneous associations. However, we analysed enough healthy subjects and IDDM patients from the same district in Japan, and the genotype frequencies did not deviate from the expected value by Hardy-Weinberg equilibrium. Furthermore, a significant difference of the allele distribution was also observed between the patients with IDDM and the patients with NIDDM, although the difference was not significant between the control subjects and the NIDDM patients.
Data derived from in vitro studies and animal models of diabetes strongly support an important role of IFN- $\gamma$ in the pathogenesis of IDDM [2], although there is little evidence in human IDDM. The reasons for the association of the IFN- $\gamma$ polymorphism with IDDM are currently unknown, but it is tempting to speculate that the polymorphism or a linked gene(s) may affect regulation of IFN- $\gamma$ gene expression. Interestingly, the first intron of the IFN$\gamma$ gene, as well as the $5^{\prime}$ region, contains a DNase Ihypersensitive site and an enhancer-like element [8].

The association of IFN- $\gamma$ was obvious when we excluded the patients whose insulin treatment started after 1 year from onset (reflecting so-called slowly progressive IDDM), and the association was highly significant in the young-onset $(<10$ years) patients (Table 1, upper panel). There was a tendency towards a frequent occurrence of clinical characteristics which reflect young or abrupt onset of diabetes or both, and depletion of insulin secretion capacity in the patients with " $3 / 6$ " or " $6 / 6$ " in comparison to the patients with other genotypes (Table 1, lower panel). These data suggest that the IFN- $\gamma$ polymorphism may contribute to the appearance of the typical symptoms of IDDM. Conversely, slowly progressive or older-onset IDDM or both, may be genetically more heterogeneous, and may include diabetes of non-autoimmune origin. In fact, recent reports showed that diabetes associated with a mitochondrial gene mutation at position 3243 preferably showed clinical characteristics compatible with slowly progressive IDDM $[9,10$ and our unpublished ob- 
servation]. Therefore, it is also suggested that proper classification by particular phenotypes may be important for disease-association studies.

There has been a growing concept that IDDM susceptibility genes comprise one major locus in the HLA complex and multiple minor loci, including the INS region. The present study suggests that the IFN$\gamma$ region may be one of the minor susceptibility genetic factors in IDDM. Although the association should be verified in other ethnic groups, our findings may provide an important clue to elucidating the pathogenesis of the disease.

Acknowledgements. We thank Dr. A.A.Like, University of Massachusetts Medical Center, for his support and his review of our manuscript. We also gratefully acknowledge the support of our colleagues in Japan, especially Dr. I. Shiraishi, Dr. T. Kitagawa, Dr. M. Owada, and Dr. Y. Akanuma.

\section{References}

1. Lucassen AM, Julier C, Beressi J-P et al. (1993) Susceptibility to insulin dependent diabetes mellitus maps to a $4.1 \mathrm{~kb}$ segment of DNA spanning the insulin gene and associated VNTR. Nature Genet 4: 305-310

2. Rabinovitch A (1993) Roles of cytokines in IDDM pathogenesis and islet $\beta$-cell destruction. Diabetes Rev 1: 215240
3. Awata T, Kuzuya T, Matsuda A, Iwamoto Y, Kanazawa Y (1992) Genetic analysis of HLA class II alleles and susceptibility to type 1 (insulin-dependent) diabetes mellitus in Japanese subjects. Diabetologia 35: 419-424

4. Matsumoto C, Awata T, Iwamoto Y, Kuzuya T, Saito T, Kanazawa Y (1994) Lack of association of the insulin gene region with type 1 (insulin-dependent) diabetes mellitus in Japanese subjects. Diabetologia 37: 210-213

5. Gray PW, Goeddel DV (1982) Structure of the human immune interferon gene. Nature 298: 859-863

6. Badenhoop K, Schwarz G, Trowsdale J et al. (1989) TNF- $\alpha$ gene polymorphisms in type 1 (insulin-dependent) diabetes mellitus. Diabetologia 32: 445-448

7. Pociot F, Mølvig J, Wogensen L, Worsaae H, Nerup J (1992) A TaqI polymorphism in the human interleukin-1 $\beta$ (IL-1 $\beta$ ) gene correlates with IL- $1 \beta$ secretion in vitro. Eur J Clin Invest 22: 396-402

8. Young HA, Hardy KJ (1990) Interferon- $\gamma$ : producer cells, activation stimuli, and molecular genetic regulation. Pharmac Ther 45: 137-151

9. Awata T, Matsumoto C, Iwamoto Y, Matsuda A, Kuzuya T, Saito T (1993) Japanese case of diabetes mellitus and deafness with mutation in mitochondrial tRNA ${ }^{\text {Leu(UUR) }}$ gene. Lancet 341: 1291-1292

10. Kadowaki T, Kadowaki H, Mori Y et al. (1994) A subtype of diabetes mellitus associated with a mutation of mitochondrial DNA. N Engl J Med 330: 962-968 